\title{
A Discussion of the Principle of Cultural Responsiveness: From Research to Practice and From History to Today
}

\author{
Robyn Stead \\ Educational Psychologist
}

\begin{abstract}
The Special Education 2000 initiative (Ministry of Education, 1998) led to the creation of the role of Resource Teachers: Learning and Behaviour (RTLB). The role was designed to support inclusion, provide consistent service, and bring about improved outcomes for students with learning and behaviour difficulties and their teachers in Years 0-10. Guiding the management and practice of RTLB is the RTLB Toolkit (Ministry of Education, 2011a). Within the Toolkit, seven principles designed to guide RTLB practice are specified. These are: inclusive teaching, culturally-responsive, ecological approach, collaborative and seamless model of practice, strengths-based, reflective, and evidencebased practice. This article focuses specifically on the principle of culturally-responsive practice. It considers current literature and key documents from the Ministry of Education and discusses a case study that draws on a kaupapa Māori framework in order to achieve better outcomes when working with Māori whānau.
\end{abstract}

\section{Research Paper}

Key words: Culturally-responsive practice, kaupapa Māori

\section{INTRODUCTION}

The notion of culturally-responsive practice is critically important to the practice of RTLB. The RTLB Toolkit (Ministry of Education, 2011a) clarifies the meaning of the culturally-responsive principle by linking it closely to another Ministry document Tatāiako: Cultural Competencies for Teachers of Māori Learners (Ministry of Education, 2011b). Tātaiako defines the competencies required for teachers of Māori learners. These competencies are:

- "Wānanga: participating with learners and communities in robust dialogue for the benefit of Māori learners' achievement
- Whānaungatanga: actively engaging in respectful working relationships with Māori learners, parents, families/whānau, hapū, iwi and the Māori community

- Manaakitanga: showing integrity, sincerity and respect towards Māori beliefs, language and culture

- Tangata Whenuatanga: affirming Māori learners as Māori. Providing contexts for learning where the language, identity and culture of Māori learners and their whānau is affirmed

- Ako: taking responsibility for their own learning and that of Māori learners" (Ministry of Education 2011 b, p.4).

In addition, the RTLB Toolkit stipulates that RTLB must meet the needs of Pasifika students and, more broadly, consider culture and identity as it affects these children and young people with whom RTLB work. The particular focus of this article is on cultural-responsiveness as it pertains to working with Māori whānau. Nairn and the National Standing Committee on Bicultural Issues (1997) make it clear that under the obligations of Te Tiriti O Waitangi (the Treaty of Waitangi) the representatives of the Crown (kāwanatanga), must work to guarantee Māori tino rangatiratanga, (autonomy, self-determination). RTLB, as representatives of the crown, have a duty as partners in the Treaty to work to ensure students receive a culturally-responsive education. Developing further understanding of how best to provide a culturally-responsive service to the partners of the Treaty will also provide insight into how to provide a culturally-responsive service in a broader sense.

\section{THE PAST}

Mead (2003) provides insight into the principles of Māori education from pre-European times and how this has affected learning for modern Māori. Mead (2003) notes that learning was highly valued in traditional Māori society, was considered tapu (holy) and strictly governed by tikanga (order). The tikanga associated with learning varied from region to region in specifics but in general followed a pattern. 
Students who demonstrated a natural talent for a specific area of learning were selected very carefully from among members of a waka confederation or iwi (people). Religion was an integral part of the teaching and learning and all aspects were governed by ritual. Teaching and learning took place in a sacred space, which was separated from the day-to-day activities of the iwi. Similarly, students were considered tapu while they were engaged in the learning activities and were required to undergo regular rituals to reduce the tapu when they were ready to re-join daily activities. The beginning and end of a course of study was marked by particular rituals, which ensured that the learning was retained. Teaching and learning was considered a communal affair with one main teacher or tohunga who was supported by teaching assistants who provided prompts when needed. Today Māori traditions are continued in a range of educational settings in a variety of ways. Māori medium settings such as Kōhanga Reo or Kura Kaupapa Māori more closely reflect the traditional (culturally-responsive) Māori pedagogy. Mainstream settings provide a variety of attempts to replicate key aspects of traditional education for Māori students. These range from tokenistic attempts to genuine provision of a culturally-responsive environment in which Māori students are able to reach their full potential as Māori.

\section{Strategies and Approaches: A Responsive Way Forward}

Alton-Lee (2003), as part of the Best Evidence Synthesis (BES) series, provides educators with ten points which characterise best-teaching practice for diverse students. Alton-Lee (2003) notes that the general make-up of the school-age population in Aotearoa/New Zealand is characterised by its diversity in terms of culture, socio-economic status as well as learning ability. The ten points are as follows:

1. "Quality teaching is focused on student achievement (including social outcomes) and facilitates high standards of student outcomes for heterogeneous groups of students.

2. Pedagogical practices enable classes and other learning groupings to work as caring, inclusive, and cohesive learning communities.

3. Effective links are created between school and other cultural contexts in which students are socialised, to facilitate learning.

4. Quality teaching is responsive to student learning processes.

5. Opportunity to learn is effective and sufficient.

6. Multiple task contexts support learning cycles.

7. Curriculum goals, resources including ICT usage, task design, teaching and school practices are effectively aligned.
8. Pedagogy scaffolds and provides appropriate feedback on students' task engagement.

9. Pedagogy promotes learning orientations, student self-regulation, metacognitive strategies and thoughtful student discourse.

10. Teachers and students engage constructively in goal-oriented assessment." (Alton-Lee, 2003, p.vi-x).

Alton-Lee has provided educators in Aotearoa/ New Zealand with a framework within which to consider their practice and whether it fits with best-practice in the area of working with diverse students. The ten points, when considered in the light of the Mead's (2003) work discussed previously, are specifically relevant to culturally-responsive education for Māori students. Point one, which is concerned with student achievement academically as well as socially, is tightly aligned with traditional Māori education where students were expected to reach a high standard of learning and were examined as part of the process to ensure that they had achieved this standard. Point three also aligns closely with Mead's (2003) discussion of the way that modern Māori education includes the tikanga of traditional education in a variety of ways. Mead gives examples of this, for example indigenising western traditions such as graduation ceremonies into a hui whakapūmau (knowledge binding), or inviting kapa haka groups to perform at education-related events.

Evidence from the area of applied psychology can be used to support the practice of RTLB under the principle of culturally-responsive practice. Macfarlane, Blampied and Macfarlane (2011) focus attention on assessment. They define assessment broadly, suggesting that it takes place as a natural and common aspect of all human interactions something that is universal. This type of assessment takes place in all phases of the RTLB intervention cycle. It starts from the moment the referral is received when assessments are made about the type of case this might be and who the best RTLB might be to work on it. Assessment continues through initial meetings to closure when the RTLB may be assessing the sustainability of the intervention and whether it is viable to close the case. Considered in this way the importance of understanding assessment when providing a culturally-responsive service is clear. Macfarlane et al., (2011) suggest that this kind of assessment helps people to make sense of, and understand, themselves and others. The key competencies (Ministry of Education, 2007) exemplify this kind of conceptualisation of assessment.

RTLB can use the key competencies as a way of understanding the situations in which they are called on to intervene. 
The New Zealand Curriculum (Ministry of Education, 2007 ) is the pivotal document under which all public education in Years 0-13 takes place. This document provides a set of key competencies which cover all the learning areas. The key competencies are developmental, designed to be taught and learned at all levels and can be used by learners to approach all the areas of the curriculum. These key competencies, thinking, using language, symbols, and texts, managing self, relating to others, and participating and contributing (Ministry of Education, 2007) can be used to understand issues of culture and are therefore integral to providing a culturally-responsive RTLB service.

One of the challenges identified by Macfarlane et al., (2011) is 'stereotype threat'. 'Stereotype threat' is activated when negative attitudes and assumptions are held by members of one group about members of others. This threat usually involves members of a majority group who may make negative assumptions about members of a minority group. It impacts negatively on achievement or performance of members of the negatively stereotyped group. Given that the majority of RTLB come from the dominant culture and that many of their clients will come from minority cultures, it is important that RTLB are aware of this challenge. Macfarlane et al., (2011) suggest a simple and effective method of countering the effect of 'stereotype threat'. This involves both parties in the interaction prior to engagement imagining a scripted intervention which is positive from beginning to end. Further details of this technique and other useful suggestions, for example, involving kaitakawaenga (cultural consultants) and kaumātua (senior Māori; elders), having an awareness of self, and to seeking out models of practice specifically designed to support cultural-responsiveness are expanded by Macfarlane et al., in their article.

Mahuika, Berryman and Bishop (2011) have provided educators with a critical review of assessment practices relevant to Māori students. An important issue which they raise is how to provide culturallyresponsive pedagogy, which does not suggest that Māori needs are so different and in some way homogeneous that they are unable to be supported by what is known to be best-practice. Instead, they suggest a starting place is to look at how Pākehā educators, as members of the dominant culture, have been unaware and unresponsive to the way that minority cultures have their differences highlighted constantly as they interact with the dominant culture. In order to remedy this situation, Pākehā educators need to make themselves aware of these differences and the inequities, which are created when teachers are members of the dominant culture. Mahuika et al.,
(2011) cite Alton-Lee (2003) specifically on formative assessment. This provides learners with information on next steps and creates opportunities for teachers to engage with students in a constructive manner as they work to improve their learning. Another important guidepost provided for RTLB in providing a culturallyresponsive service is the concept of agentic teachers. Mahuika et al., (2011) suggest that it is important for educators not to become caught up in what they cannot control, such as a student's socio-economic status or previous educational history. Instead, they provide a model of an agentic teacher who theorises in a positive way about the opportunities education can provide a student. Other suggestions made by Mahuika et al., (2011) include inquiry teaching and learning, and the use of portfolio assessment rather than heavy reliance on summative assessment, which does not allow for continuous teaching and learning cycles.

Bevan-Brown has written extensively (2000, 2003, 2011) on the theme of ensuring that the educational systems and programmes used by schools and teachers are culturally-responsive. By way of these publications she has created a framework which is user-friendly, flexible and non-prescriptive. Educators, including RTLB, can use this framework to consider the strengths and weaknesses of the services provided in light of cultural-responsiveness. The framework includes eight principles which have been identified as pivotal to Māori culture in relation to education. Each principle is supported by questions to guide inquiry into it. The model is cyclical rather than static, with the expectation that professionals will continue to engage with it and make changes in practice to improve outcomes for Māori students.

A kaupapa Māori framework for professionals working directly with individual Māori students is Te Pikinga ki Runga: Raising possibilities (Macfarlane, 2009). Te Pikinga ki Runga includes both the key competencies (Ministry of Education, 2007) and Te Tiriti o Waitangi as integral to the work. In some ways, this model could be compared to the work of Durie (1998) on models of Māori health and wellbeing such as Whare Tapa Whā, or Pere on Te Wheke (Pere, 1988). What makes Te Pikinga ki Runga unique is that it has been designed specifically with education in mind. Notably, it does not include the concept of wairua or spiritually. Macfarlane (2009) argues for this exclusion by saying that there is a consensus among both Māori and non-Māori that educators do not have the skills to respond appropriately to this aspect of the Māori worldview. An important feature of Te Pikinga ki Runga (Macfarlane, 2009) is the Te Huia grid, which is a set of guiding questions from the body of the framework under the Protection principle of the Treaty of 
Waitangi. This is defined in terms of education as enhancing the well-being of the tamaiti in the domains of hononga (relational aspects), hinengaro (psychological aspects), tinana (physical aspects) and mauri (essence and potential). As part of my work as an RTLB I have used Te Pikinga ki Runga (Macfarlane, 2009) as I work to be culturally-responsive.

\section{Practical Application of the Model or Perhaps just Case Study?}

Manu (name has been changed to preserve confidentiality) has a cultural background which is both Pasifika and Māori. The whānau has strong roots in both cultures and both cultures are robustly represented in the current life of this student. Manu was referred to the RTLB service because of outbursts in which he threatened to harm himself. The school requested support to reduce the intensity and frequency of these outbursts. Initial data gathering demonstrated that Manu had developed a good relationship with his classroom teacher and with one of the deputy principals in the school. His teacher could identify when Manu was beginning to become overly-aroused which led to self-harm. When this happened, she was able to call the deputy principal who would take Manu to her office for some time-out. Manu was eventually able to calm himself and would return to class. Manu was struggling to achieve at similar levels to his peers and was receiving targeted reading and writing instruction but was continuing to make slow progress towards his learning goals. Discussion with Manu and observation indicated that Manu responded positively to rewards such as table points, lollies and certificates of recognition at weekly assemblies. After an initial meeting with Manu's family to gather some background information, the team agreed to have a collaborative meeting to discuss the situation and decide what would be the best way to intervene to support Manu. When I made the appointment with the whānau, I talked about Te Pikinga ki Runga and asked if they thought this might be a useful tool for us. Both parents were keen to try it.

We began by talking about the format of Te Pikinga ki Runga and how it reflected the principles of the Treaty of Waitangi, the key competencies, as well as Te Huia. The information which came out of this meeting was rich and relevant to the situation. Both parents were present and shared the contexts of their families as it had meaning for their son. It became clear that within the extended family there were many strengths and that Manu was part of an interconnected chain of people. After reflection, the team agreed that Manu was experiencing grief and loss associated with the death of his maternal grandparents. This was compounded by his eldest sister's recent move away overseas. Some of the information shared by the school at this meeting confirmed that Manu associated this move with the death of his grandparents. The extreme nature of Manu's outbursts was more understandable to the team once we clarified that he seemed to believe that his sister and her children were gone permanently in the same way that his grandparents were gone from his life.

The interventions discussed reflected the rich information which came through as we discussed Te Huia. The whānau made plans to consult rangatira who could help Manu to clarify grief and loss, and to come to a more healthy understanding of his grandparents' deaths and his sister's move. The school discussed a programme which was running in the school specifically for children to work through grief and loss, and, with the permission of his parents, scheduled Manu to become involved in this group. The team agreed on a behaviour plan to work with Manu's competitive nature by teaching some desired behaviours and provide the kinds of rewards he preferred when he demonstrated these positive behaviours. A learning intervention plan was created which focused on teaching of decoding skills using Nicholson's reading lessons from the Phonics Handbook (Nicholson, 2005). This evidence-based programme provides small and achievable steps for the learner so that Manu was able to gain a sense of success in his daily literacy lessons, which rewarded him for making steady progress. Finally, Manu's parents decided to use Skype more frequently so that Manu could talk to his sister and her children as often as he wished, to continue to build confidence that these relationships were on-going.

Some of the outcomes from this meeting are that Manu is now making steady progress with his literacy learning. He has improved two reading levels in one term, his literacy programme teacher reports that he is always on time for lessons, is wellprepared and ready to engage with the learning. There has been a reduction in the incidences of extreme behaviour. Manu's parents report that they are pleased with his progress and he is doing well at home. He is just beginning the school-based programme for children who have experienced grief and loss, and the team are tailoring the behaviour support plan to manage some new behaviours which have emerged but are significantly less-challenging than the original behaviours. 


\section{CONCLUSION AND PERSONAL REFLECTIONS}

Te Pikinga ki Runga provides a place for RTLB to start their work with Māori families. As a practitioner who stands outside this culture and is a member of the dominant Pakeha culture I can use this as my guide. A point which Mead (2003) raises is that, to Māori, knowledge is sacred and as such, tapu. It is my belief that the situation described above has developed in a positive way because the family understood that I respected them and their son, and that my sole aim was to work to create the conditions that would make it possible for him to be successful on his own terms. As a professional, I place myself on a continuum of cultural understanding. A danger for all professionals is that we do not know what we do not know. In order to learn more about this we have to be prepared to take risks, look for insights in the literature and ask for feedback from those with whom we interact.

RTLB are in a unique and privileged position within education. We have the opportunity to have influence in a wide range of schools and with a wide range of students, teachers and families. We are able to interact with whānau in ways that it is sometimes difficult for teachers to do as we can be seen as independent from individual schools. The challenge associated with this is that we do not always have the consistent support of cultural advisors as we provide our service. It is our job as professionals to turn to the literature, attend quality professional development and to use the tools we have at hand to ensure that the students, schools and families we serve are able to succeed on their own terms as Māori, Pasifika or any other culture. We are at a point in time in the development of our country and our profession where there is a wide range of literature and research available to us to provide guidance on culturalresponsiveness. The New Zealand Curriculum (Ministry of Education, 2007) has embedded within it the key competencies which are tools we can use to support cultural-responsiveness. Documents such as Tātaiako and Ka Hikatia (Ministry of Education, 2011 b) provide specific guidance in best practice for teachers and for teaching Māori students. My own experience in working in a culturally-responsive manner is that all that I learn has relevance for all the students I work with. As I learn more about being culturally-responsive, I become a more responsive practitioner for all my students.

\section{REFERENCES}

Alton-Lee, A. (2003). Quality teaching for diverse students in schooling: Best evidence synthesis. Wellington: Ministry of Education.

Bevan-Brown, J. (2000). A cultural audit for teachers: Looking out for Maori learners with special needs. set, Research Information for Teachers, (1), 16-20.

Bevan-Brown, J. (2003). Cultural self-review: Providing culturally effective, inclusive, education for Maori learners. Wellington: New Zealand Council for Educational Research.

Bevan-Brown, J. (2011). He waka tino whakarawea: A model for evaluating the cultural appropriateness and effectiveness of programmes and services for Maori learners both with and without special needs. Kairaranga, 12 (2), 27-35.

Durie, M. (1998). Whaiora: Maori health development (2nd ed). Auckland: Oxford University Press.

Macfarlane, A. H., Blampied, N. M., \& Macfarlane, S. $H$. (2011). Blending the clinical and the cultural: A framework for conducting formal psychological assessment in bicultural settings. New Zealand Journal of Psychology, 40 (2), 5-15.

Macfarlane, S. (2009). Te pikinga ki runga: Raising possibliities. set: Research Information for Teachers, 2, 42-50. Wellington: NZCER.

Mahuika, R., Berryman, M., \& Bishop, R. (2011). Issues of culture and assessment in New Zealand education pertaining to Maori students. Assessment Matters, 183-198.

Mead, H. (2003). Tikanga Maori: Living by Maori values. Auckland: Huia Press.

Ministry of Education (1998). Special Education 2000. Getting it right together. Wellington, NZ. Author.

Ministry of Education (2007). The New Zealand curriculum for english-medium teacher and learning in years 1-13. Wellington: Learning Media.

Ministry of Education (2011a). Toolkit: Resource Teacher of Learning and Behaviour. Wellington: Ministry of Education.

Ministry of Education (2011b). Tàtaiako. Cultural competencies for teachers of Māori learners. Wellington, NZ: Author. 
Nairn, R., \& National Standing Committee on Bicultural Issues (1997). Cultural justice and ethics in psychological practice. In $\mathrm{H}$. Love \& W. Whittaker (Eds.), Practice issues for clinical and applied psychologists in New Zealand (pp. 127135). Wellington, New Zealand: New Zealand Psychological Society.

Nicholson, T. (2005). The phonics handbook. Padstow: Whurr Publishers Ltd.

Pere, R. R. (1988). Te wheke: Whaia te maramatanga me te aroha. In S. Middleton (Ed.).

Women in Education in Aotearoa. Wellington, New Zealand: Allen \& Unwin/Port Nicholson Press.
AUTHOR PROFILE

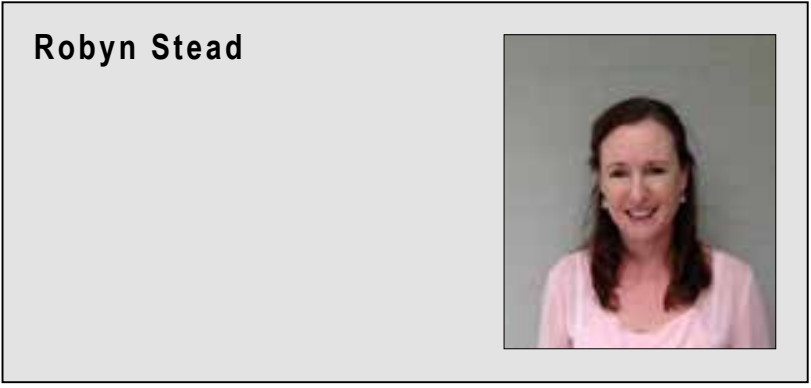

Robyn Stead is an Educational Psychologist who works as a Practice Leader in the Howick/Pakuranga/ Flatbush/South Otara RTLB cluster. Robyn has taught in both the United States and New Zealand which has given her an interest in, and opportunities to learn about, working in a culturally-responsive way. A chance meeting with a senior Māori educator and some challenging questioning prompted her to learn more about Te Pikinga ki Runga as a way of supporting the work of RTLB.

\section{Email:}

stead@pakarangaint.school.nz 